\title{
Sexual size dimorphism in Ground Beetles and its modeling in latitude gradient
}

\author{
Sukhodolskaya Raisa A. ${ }^{1}{ }^{*}$, Saveliev Anatoliy A. ${ }^{2}$, Gordienko Tatyana A. ${ }^{1}$, Vavilov Dmitriy N. ${ }^{1}$ \\ ${ }^{1}$ Laboratory of Biomonitoring Institute of Ecology and Mineral Resource Management Academy of Sciences of Tatarstan \\ Republic, Kazan, Tatarstan, Russia. \\ ${ }^{2}$ Kazan (Volga Region) Federal University, Kazan,Tatarstan, Russia.
}

Publication history: Received on 22 January 2018; revised on 03April 2018; accepted on 12 April 2018

\author{
https://doi.org/10.30574/gscbps.2018.3.1.0009
}

\begin{abstract}
Large-scale systematic patterns of variation lie in the heart of organismic biology and have interested biologists ever since the beginning. These are most obvious in terms of body size, probably the single most important quantitative trait of an individual. In this relation Ground Beetles are poorly studied, though they are regarded to be sensitive to environmental changes and are accepted bioindicators. Beetles were sampled in 8 provinces of Russia, situated at different latitudes. We measured elytra length in six paleartic eurytopic species of carabids. We used mixed linear models to infer the mean latitude effect on size and sexual dimorphism of females and males. Regression coefficients in both sexes were negative and differed in different species. In C. cancellatus, C.hortensis, $P$. niger modulus of regression coefficients were larger in females, then, in that species females were more variable than males. In $C$. granulates and $P$. melanarius modulus of regression coefficients were larger in males, then, in those species males were more variable in latitude gradient. It is noteworthy that species, sharing the same ecological niches, had different strategies in realizing sex - specific body size variation in latitude gradient. E. g., C. granulatus - C. cancellatus, P. niger - P. melanarius. In general body size decreased in latitude gradient both in females and males. Shifts were steeper in Carabus species, than in Pterostichus. Despite SSD occurred in some analyzed latitudes and mainly at the margins of area, modeling results did not confirm opinion that SSD systematically changes in latitude gradient.
\end{abstract}

Keywords: Carabids; Size variation; Sexual size dimorphism; Latitude gradient; Linear models

\section{Introduction}

The study of latitudinal variation in organism size both within and between species has a long tradition, since Bergmann's work on mammals, describing the individual tendency to be larger in cold environments [1]. This has been of interest because it may reflect important ecological interactions between the organisms and their environment, and because it may help in understanding the evolutionary dynamics of size and growth patterns in relation to latitudinal varying selection pressures [2-5]. In the case of ectotherms either invertebrate or vertebrate, several hypotheses concerning body size variation have also been proposed reflecting the evidence that some groups follow Bergmann's rule, some show converse or compound patterns, and some do not show any pattern at all. Converse Bergmannian clines are much more frequent in ectotherms than in endotherms, especially in insects [6, 7]. Body size in insects probably obeys to different ecophysiological factors and evolutionary pressures than those in endotherms. Body size and mass are one of the basic features that influence all other aspects of biology, size and mass correlates with fitness as well act as determinants of fitness. Thus these two components have formed targets of natural selection [8]. Male and females of almost all animals differ in their body sizes; this phenomenon is referred to sexual size dimorphism (SSD). The degree and direction of this dimorphism vary considerably among taxa including the population within the species. Major amount of this variation is considered to be due to sex differences in body size plasticity. Concerning SSD second

\footnotetext{
${ }^{*}$ Corresponding author

E-mail address: sukhodolskayaraisa@gmail.com
}

Copyright (C) 2018 Author(s) retain the copyright of this article. This article is published under the terms of the Creative Commons Attribution Liscense 4.0. 
prominent body size pattern is Rensch's rule, the observation widespread in the animal kingdom that male body size varies (or evolutionarily diverges) more than female body size among related species, such that male-biased sexual size dimorphism increases and female-biased sexual size dimorphism decreases with body size [9-11]. Currently, there are abundant data for a variety of taxa showing that body size also varies geographically and that such variation can be more prominent in one of the sexes, affecting the direction and magnitude of SSD [12-14]. In particular, it has been shown that body size and sexual size dimorphism of $S$. limbatus varied considerably with latitude; beetles were smaller but more dimorphic at lower latitudes [15-16].

In all cited papers body size variation in latitude gradient was presented in the simple scalar values. The authors did not take into account that samples, taken at different latitudes, had been taken in different environment too (i. e. level of anthropogenic disturbance, vegetation cover etc.). In our study we tried to overcome those difficulties. To the first time we used linear models to clarify latitude impact on sexual size variation in insects. Moreover, we used two types of the modeling to improve data discussion.

The aim of the paper was to purify the influence of geographical position of sampled beetles to the sexual size dimorphism in six investigated traits in Ground Beetles. The latter are regarded as bioindicators, but information on their intraspecific size variation is scarce.

In our previous works we showed that all studied species of carabids had female-biased sexual size dimorphism practically in all six traits, but the value of sexual dimorphism in various traits differed significantly [17].

\section{Material and methods}

\subsection{Collection sites and insect sampling}

Wild specimens of carabids were sampled in 1996 - 2012 in different provinces of Tatarstan Republic (53 sites). Specimen from other regions of Russia were kindly presented to us from our colleagues from Perm, Kemerovo, Stavropol, Udmurtia, Mariy El Universities, Institute of Systematic and Zoology UD RAN and Visim Reserve (Figure 1 and Table 1).

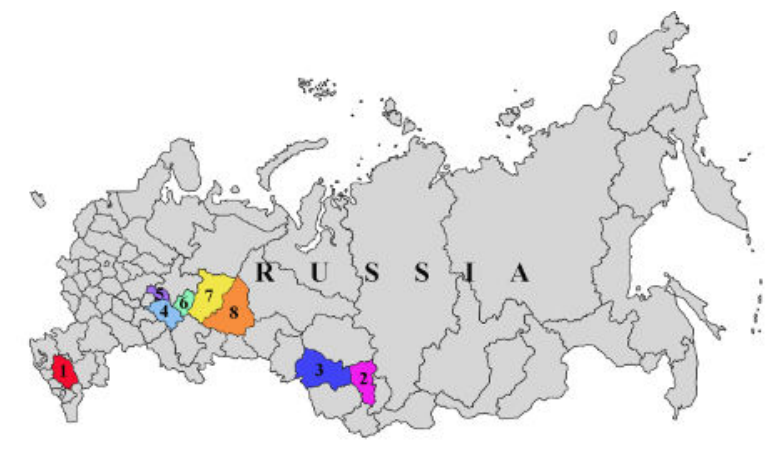

Figure 1Map of the studied territory

Table 1 List of locations involved in study

\begin{tabular}{llccccc}
\hline $\begin{array}{c}\text { Sr. } \\
\text { No. }\end{array}$ & \multicolumn{1}{c}{ Region } & $\begin{array}{c}\text { Latitude } \\
\left({ }^{\circ} \mathbf{N}\right)\end{array}$ & $\begin{array}{c}\text { Longitude } \\
\left({ }^{\circ} \mathbf{E}\right)\end{array}$ & $\begin{array}{c}\text { Number of } \\
\text { sites }\end{array}$ & Type of habitats & Sample size \\
\hline 1 & Stavropol region & $45^{\circ} 02^{\prime}$ & $41^{\circ} 55^{\prime}$ & 6 & Meadow, birch & 76 \\
2 & Kemerovo region & $54^{\circ} 56^{\prime}$ & $87^{\circ} 14^{\prime}$ & 20 & Meadows, birch, lawn & 1954 \\
3 & Novosibirsk region & $55^{\circ} 27^{\prime}$ & $79^{\circ} 33^{\prime}$ & 14 & Meadows, farmlands & 360 \\
4 & Tatarstan Republic & $55^{\circ} 47^{\prime}$ & $49^{\circ} 06^{\prime}$ & 53 & Meadow, birch, oak, elm & 11312 \\
5 & Mari El Republic & $56^{\circ} 42^{\prime}$ & $4752^{\prime}$ & 14 & Meadow, birch, oak & 67 \\
6 & Udmurtia Republic & $57^{\circ} 17^{\prime}$ & $52^{\circ} 45^{\prime}$ & 16 & Birch, oak, elm & 396 \\
7 & Cis_Ural & $57^{\circ} 01^{\prime}$ & $57^{\circ} 9^{\prime}$ & 21 & Birch, oak, elm & 58 \\
8 & Sverdlovsk region & $58^{\circ} 42^{\prime}$ & $61^{\circ} 20^{\prime}$ & 6 & Meadow & 458 \\
\hline
\end{tabular}




\subsection{Study organisms}

We analyzed six carabid species: Carabus granulatus L., 1758, Carabus cancellatus Ill., 1798, Carabus hortensis, Pterostichus melanarius Ill., 1798, Pterostichus niger Schall, 1783, Poecilus cupreus L., 1758. All of them are widespread in Paleartic, generalists, zoophagous and mesophilous.

\subsection{Morphometric analysis}

All measurements were made with a Leitz RS stereoscopic dissecting microscope at a magnification of 10 diameters, using a calibrated ocular grid with a scale interval of $0.1 \mathrm{~mm}$. For each of specimens six variables were measured, including: elytra length and width, pronotum length and width, head length and distance between eyes.

\subsection{Statistical analysis}

All statistical analyses of the morphometric data were performed using R system. Profound description of statistical procedures was presented in our earlier publications [18]. At first we modeled latitude contribution into elytra length variation, which was species-specific. Here we emphasize that models like those gave the possibility to separate the influence of the habitat geographic location on the body size variation in studied species of carabids. In other words, our results reflect body size deviations caused by the geographic location (latitude) with influence of other environmental factor (anthropogenic effect, vegetation etc.) filtered out. As a references we used Tatarstan as the center of the area of the studied carabids species. The dependence on latitude was considered to be specific for males and females, so the effect of sex was taken into account (model include sex and its interaction with latitude). For example, the model which estimated the variation of elytra length was written as follows (using the R syntax): ****

$$
\text { Elytra. Length fSex/(fRegion + fAnthropogen + fHabitat + fIsolation) }
$$

Where, fSex - the factor, representing sex, fRegion- factor, representing the latitude etc. Analysis of variance (ANOVA) was used to estimate effects significance. Estimated effects and their confidence intervals were used to plot modeling results in figures and tables; interaction effects were compared with that of the reference value. Besides the confidence intervals for the main effects of sex and some other variables were also displayed.

Obtained elytra length values, specific for each studied latitude, were used then to model the impact of latitude to elytra length and SSD variation. In case of application of a simple linear model for a few locations, the main latitude effect is masked by the species effects at locations. So we used linear mixed model to infer the mean latitude effect on females mean size, males mean size and sexual size dimorphism. Model included latitude as a fixed effect (averaged over all species), and a random slope and random intercept effects, representing species specific. To estimate significance of the fixed latitude effect we used both the approximate Student test and models comparison using likelihood-ratio test.

Elytra length variation, caused by the influence of habitation on certain latitude, were used to plot figures. The same values were used to calculate Lovich and Gibbons's [19] preferred index of sexual size dimorphism, SSD = (elytra length in females/elytra length in males)-1, at certain latitude.

In order to estimate parameters significance we compared two models:

1. Fmean.lme0: Fmean $\sim 1+(1 \mid$ fSpec $)$

2. Fmean.lme1: Fmean $\sim$ Lat + (Lat $\mid$ fSpec).

Into the second model parameter "latitude" was included.

For latitude impact on SSD we also used and compared two models:

1. SDmean.lme0: SDmean $\sim 1+(1)$ fSpec

2. SDmean.lme1: SDmean $\sim 1+$ Lat $+(1+$ Lat $\mid$ fSpec $)$

\section{Results}

In all studied species elytra length tended to decrease towards the high latitudes (Figure 2).We found significant effect of latitude on females and males body size in studied species of carabids (Table 2). The same results for each studied species in particular showed that carabids body size decreased towards the high latitudes. 


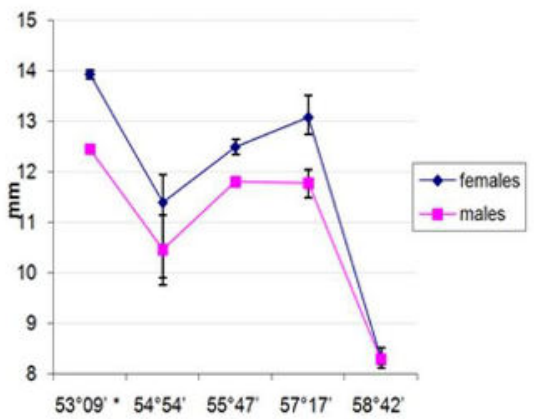

A

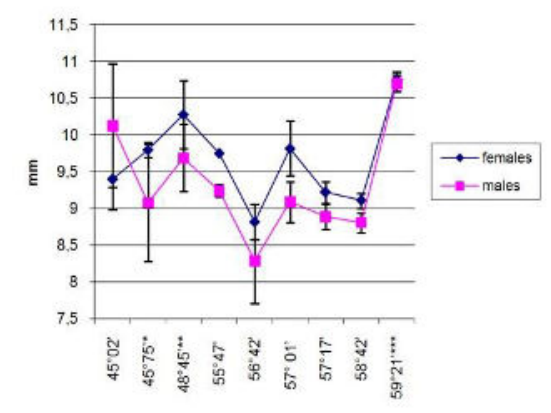

D*

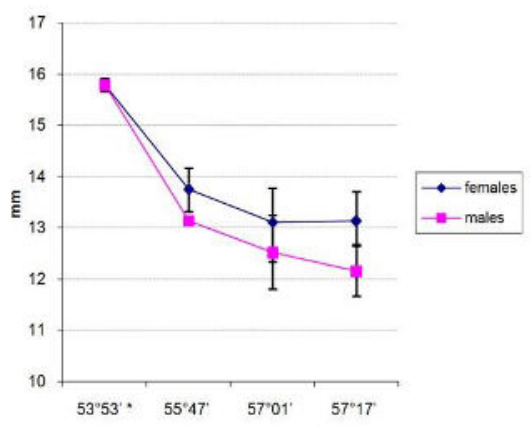

B

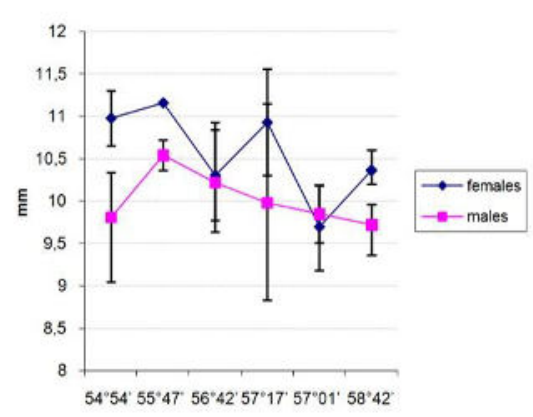

$\mathrm{E}$

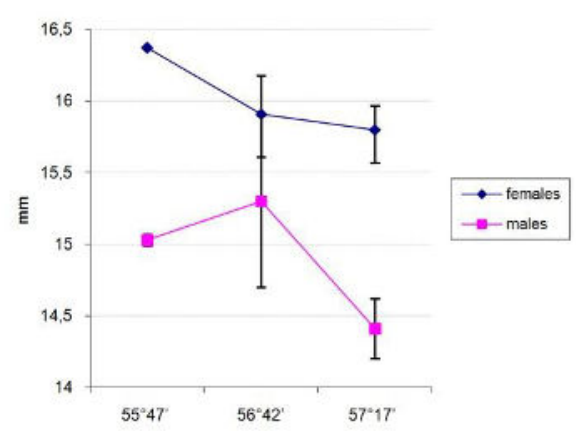

C

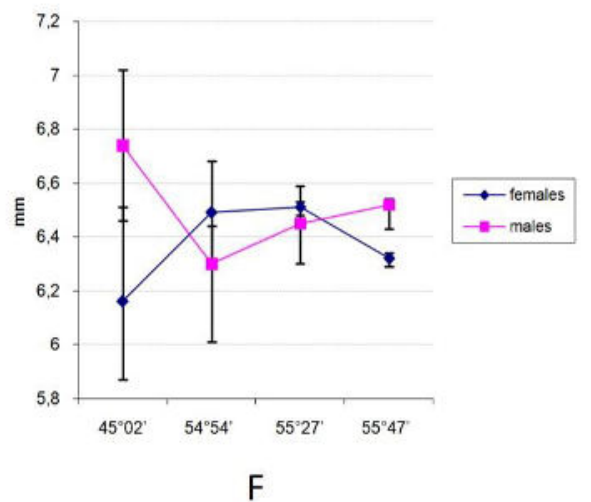

Figure 2 Elytra length variation in studied species of carabids

A - C. granulates, B - C. cancellatus, C - C. hortensis, D - P. melanarius, E - P. niger, F - Poec. cupreus

* - data taken from V. Brygadyrenko, O. Korolev [20].

Table 2 Modeling results of latitude impact on mean elytra length in studied species of carabids

\begin{tabular}{|c|c|c|c|c|c|c|c|c|c|c|}
\hline & \multicolumn{5}{|c|}{ Females } & \multicolumn{5}{|c|}{ Males } \\
\hline & Value & $\begin{array}{c}\text { Std. } \\
\text { Error }\end{array}$ & DF & t-value & p-value & Value & $\begin{array}{c}\text { Std. } \\
\text { Error }\end{array}$ & DF & t-value & p-value \\
\hline (Intercept) & 11,83 & 1,42 & 24 & 8,30 & 0,0000 & 11,23 & 1,28 & 24 & 8,76 & 0,0000 \\
\hline Latitude & $-0,33$ & 0,15 & 24 & $-2,24$ & 0,0343 & $-0,31$ & 0,13 & 24 & $-2,38$ & 0,0254 \\
\hline
\end{tabular}

Table 3 Coefficients of regression "females size: latitude" and "males size: latitude" in analyzed species of carabids

\begin{tabular}{lllll}
\hline & \multicolumn{2}{c}{ Females } & \multicolumn{2}{c}{ Males } \\
& (Intercept) & Latitude & (Intercept) & Latitude \\
\hline C. granulatus & 12,28 & $-0,46$ & 11,29 & $-0,57$ \\
C. cancellatus & 14,57 & $-0,56$ & 14,08 & $-0,36$ \\
C. hortensis & 16,93 & $-0,75$ & 15,74 & $-0,69$ \\
P. melanarius & 9,57 & $-0,04$ & 9,19 & $-0,06$ \\
P. niger & 10,95 & $-0,25$ & 10,35 & $-0,22$ \\
Poec. cupreus & 6,67 & 0,07 & 6,73 & 0,03 \\
\hline
\end{tabular}

Results on latitude impact on beetles' size showed that the second model was better: significance level of "latitude" was high, well then latitude affected body size variation in studied species of carabids (Table 4). 
Table 4 Results of models comparison

\begin{tabular}{lllllllll}
\hline & Df & AIC & BIC & logLik & deviance & Chisq. & ChiDf & Pr(>Chisq) \\
\hline Fmean.Ime0 & 3 & 120,18 & 124,48 & $-47,09$ & 114,18 & & & \\
Fmean.Ime1 & 6 & 117,34 & 125,94 & $-52,67$ & 105,34 & 8,84 & 3 & 0,0315 \\
Mmean.Ime0 & 3 & 114,86 & 119,17 & $-54,43$ & 108,86 & & & \\
Mmean.Ime1 & 6 & 111,27 & 120,27 & $-49,84$ & 00,67 & 9,20 & 3 & 0,0268 \\
\hline
\end{tabular}

Abbreviations used: Df - degrees of freedom; AIC - Akaike information criterion; BIC - Bayesian information criterion; LogLik - logarithm of likelihood coefficient; Chisq. - Chi-squared distribution; CHiDf-describes random numbers for a Chi-sqared distribution; Pr( $>$ Chisq) - Chi-Square test statistic, associated with p-value.

Figure 3 shows variation in SSD values: there was no regular tendency in that variation. In two species the value of SSD decreased in latitude gradient, in two species - increased and in two species remained unchanged. Linear modeling showed that there was no dependence of that parameter for latitude (Table 5). In studied species regression coefficients had the opposing directions (Table 6). Two models used did not find latitude effect on SSD variation (Table 7).

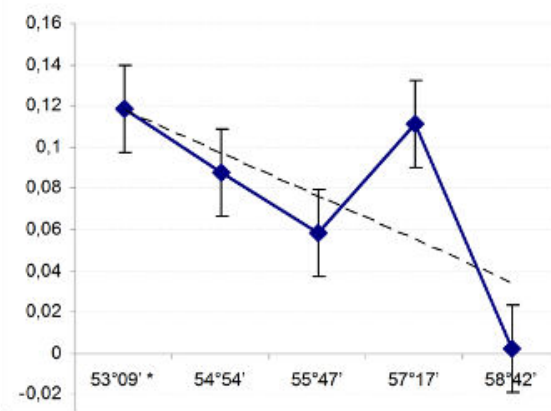

A

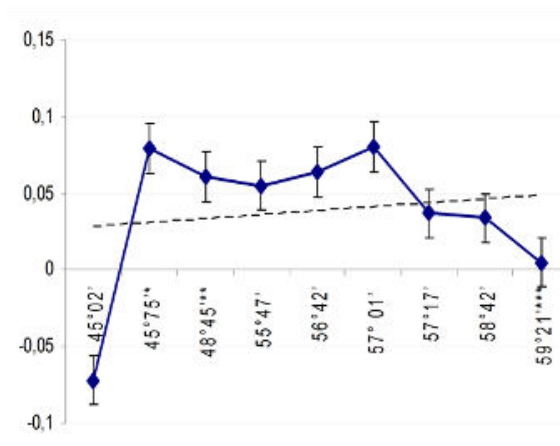

D

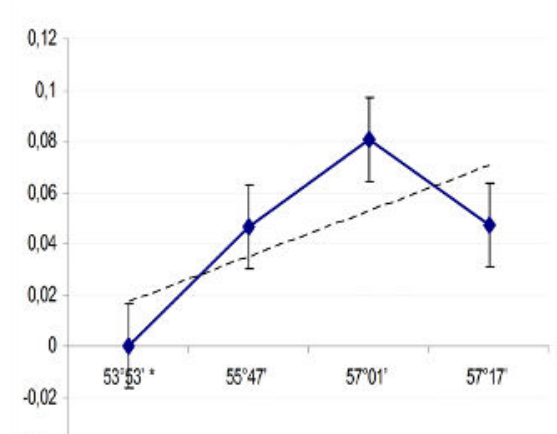

B

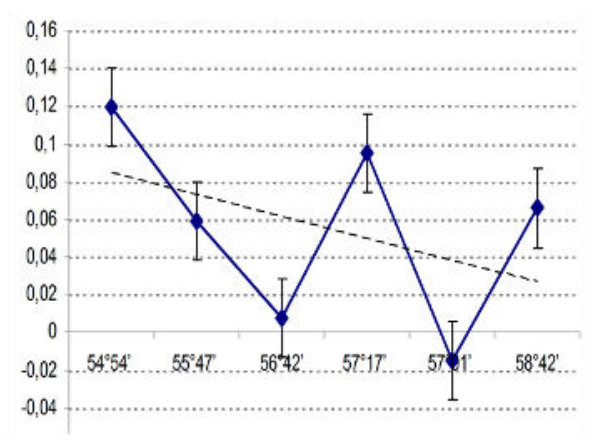

E

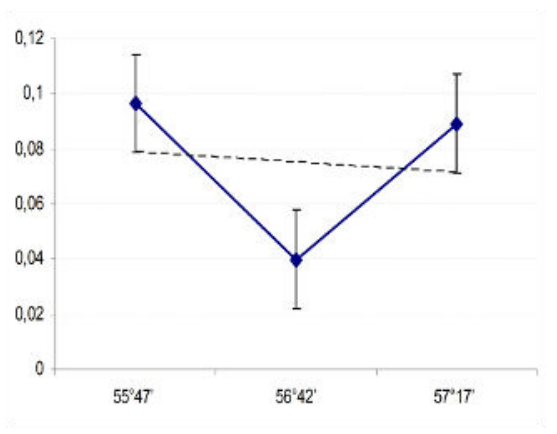

$\mathrm{C}$

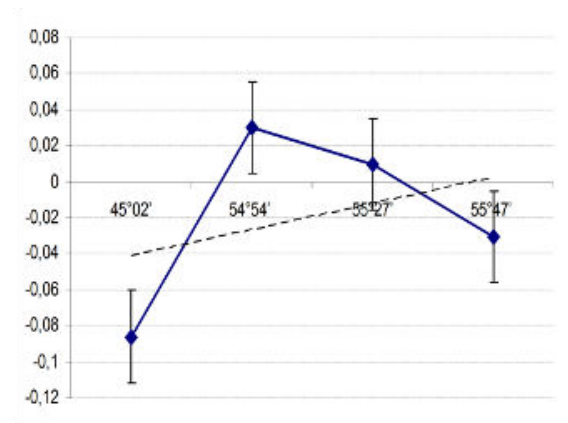

F

Figure 3 SSD in elytra length variation in studied species of carabids A - C. granulates, B - C. cancellatus, C - C. hortensis, D - P. melanarius, E - P. niger, $\mathrm{F}-$ Poec. cupreus

Table 5 Mean coefficients of regression in SSD in carabids for latitude (models fixed effects: SDmean $\sim$ Lat)

\begin{tabular}{lcccc}
\hline & Value & Std. Error & t-value & p-value \\
\hline (Intercept) & 0,56 & 0,17 & 3,36 & 0,0001 \\
Latitude & $-0,02$ & 0,04 & $-0,38$ & 0,3520 \\
\hline
\end{tabular}


Table 6 Coefficients of regression "SD:latitude" and in analyzed species of carabids

\begin{tabular}{lcc}
\hline & \multicolumn{2}{c}{ Females } \\
& (Intercept) & Latitude \\
\hline C. granulatus & 0,91 & $-0,09$ \\
C. cancellatus & 0,34 & 0,03 \\
C. hortensis & 0,96 & $-0,09$ \\
P. melanarius & 0,36 & 0,02 \\
P. niger & 0,61 & $-0,03$ \\
Poec. cupreus & 0,16 & 0,07 \\
\hline
\end{tabular}

Table 7 Results of models comparison

\begin{tabular}{|c|c|c|c|c|c|c|c|c|}
\hline & Df & AIC & BIC & logLik & deviance & Chisq. & ChiDf & $\operatorname{Pr}(>$ Chisq) \\
\hline SDmean.lme0: SDmean $\sim 1+(1 \mid$ fSpec $)$ & 3 & 54,20 & 58,51 & $-24,10$ & 48,21 & & & \\
\hline SDmean.lme1:SDmean 1+Lat+(1+Lat| fSpec) & 6 & 56,88 & 65,48 & $-22,44$ & 44,88 & 3,33 & 3 & 0,3438 \\
\hline
\end{tabular}

\section{Discussion}

There are many examples in Coleoptera showing intraspecific body size variation, and some of them efficiently analyzed the relative importance of plasticity and local adaptation in the detected patterns. Current approaches have also demonstrated that plasticity in body size can differ between sexes, thereby producing variation in SSD among populations of the same species [21]. In this relation Orthoptera is sufficiently well studied. In grasshoppers researchers found the existence of morphometrical differences among populations and a pattern of geographical variation, with males and females from eastern populations being larger than the ones from the west. Sexual size dimorphism was also detected and its value increased with latitude [22]. In another publication, when several traits in grasshopper Dichroplus pratensis, they showed different variance in latitude gradient [7] with SSD being the largest in the center of area. Those results agree with our previous studies, where it had been shown that different traits responded in different directions under the same factor impact [23]. In this paper the only elytra length was taken into account. Scalar values of it varied similarly in both sexes in relation to latitude. Only in 5 analyzed cases shifts in elytra length value towards the north had opposite directions. In some cases that lead to SSD (see, C. hortensis, P. niger, P. cupreus at high latitudes). So in our study the mean body size decreased towards the high latitudes in females and males as well, regression coefficients were negative in all studied species. But their modulus in females was slightly larger than in males. Then, decrease in body size with latitude on average was steeper for females than males. That disagreed with paper by Blanckenhorn et al. [24]. Regression coefficients in both sexes differed in different species. In $C$. cancellatus, $C$. hortensis, $P$. niger modulus of regression coefficients were larger in females, then, in that species females were more variable than males. In $C$. granulates and $P$. melanarius modulus of regression coefficients were larger in males, then, in those species males were more variable in latitude gradient. It is noteworthy that species, sharing the same ecological niches, had different strategies in realizing sex - specific body size variation in latitude gradient. E. g., C. granulatus - C. cancellatus, P. niger P. melanarius. We can add also, that body size decrease in latitude gradient both in females in males were steeper in Carabus species, than in Pterostichus.

Despite SSD occurred in some analyzed latitudes and mainly at the margins of area (Fig. 3), modeling results did not confirm opinion than SSD systematically changes in latitude gradient. 


\section{Conclusion}

Studied six species of carabids follow converse Bergmann rule, when elytra length decreases toward the high latitudes. Observed phenomena can be explained by temperature constraints, when the vegetation season shortens and it is not enough time to larva growth. Decrease in body size with latitude was on avarge steeper for females than males. Sexual size dimorphism variation is not affected by latitude as it has been noted for several species from another taxa.

\section{Compliance with Ethical Standards}

\section{Acknowledgments}

The authors thank Prof. N. Eremeeva, Prof. V. Mordkovich, Prof. L. Esyunin, Prof. E. Chenikalova, Dr. S. Dedyukhin, Dr. V. Matveev and Dr. N. Ukhova for beetles collection from different provinces of Russia for the purposes of morphometric analysis.

\section{Disclosure of conflict of interest}

The authors have no conflict of interest to declare.

\section{References}

[1] Bergmann C. (1847). Uber die verhaltnisse der warmeokonomie der thierezuihrer grosse. Gottinger Studien Teil, $1,595-708$.

[2] Partridge L and French V. (1996). Thermal evolution of ectotherm body size: why get big in the cold. Animals and temperature: Phenotypic and evolutionary adaptation, 59, 265.

[3] Parsons KE. (1997). Contrasting patterns of heritable geographic variation in shell morphology and growth potential in the marine gastropod Bembicium vittatum: evidence from field experiments. Evolution, 51(3), 784796.

[4] Terribile LC, Olalla-Tarraga MA, Diniz-Filho JAF and Rodríguez MA. (2009). Ecological and evolutionary components of body size: geographic variation of venomous snakes at the global scale. Biological Journal of the Linnean Society, 98(1), 94-109.

[5] Chauvaud L, Patry Y, Jolivet A, Cam E, Le Goff C, Strand O, Charrier G, Thebault J, Lazure P, Gotthard K and Clavier J. (2012). Variation in size and growth of the great scallop Pecten maximus along a latitudinal gradient. PloS one, $7(5)$, e37717.

[6] Blanckenhorn WU and Demont M. (2004). Bergmann and converse Bergmann latitudinal clines in arthropods: two ends of a continuum? Integrative and Comparative Biology, 44(6), 413-424.

[7] Bidau C J and Marti DA. (2007). Dichroplus vittatus (Orthoptera: Acrididae) follows the converse to Bergmann's rule although male morphological variability increases with latitude. Bulletin of entomological research, 97(1), 69-79.

[8] Whitman DW. (2008). The significance of body size in the Orthoptera: a review. Journal of Orthoptera research, $17(2), 117-134$.

[9] Rensch B. (1950). Die Abhängigkeit der relativen Sexualdifferenz von der Körpergrösse. Bonner Zoologische Beiträge, 1, 58-69.

[10] Abouheif E and Fairbairn DJ. (1997). A comparative analysis of allometry for sexual size dimorphism: assessing Rensch's rule. The American Naturalist, 149(3), 540-562.

[11] Storz J F, Balasingh J, Bhat HR, Nathan PT, Doss DPS Prakash AA and Fairbairn DJ. (2007). Sexual dimorphism in the water strider, Aquarius remigis: a case study of adaptation in response to sexually antagonistic selection. Sex, size and gender roles: evolutionary studies of sexual size dimorphism. Oxford Univ. Press, Oxford, UK, 97-105.

[12] Zamudio KR. (1998). The evolution of female-biased sexual size dimorphism: A population-level comparative study in horned lizards (Phrynosoma). Evolution, 52(6), 1821-1833.

[13] Kunz TH. (2001). Clinal variation in body size and sexual dimorphism in an Indian fruit bat, Cynopterus sphinx (Chiroptera: Pteropodidae). Biological Journal of the Linnean Society, 72(1), 17-31. 
[14] Tamate T and Maekawa K. (2006). Latitudinal variation in sexual size dimorphism of sea-run masu salmon, Oncorhynchus masou. Evolution, 60(1), 196-201.

[15] Roitberg BD. (2007). Why pest management needs behavioral ecology and vice versa. Entomological Research, 37(1), 14-18.

[16] Koivula MJ. (2011). Useful model organisms, indicators, or both? Ground beetles (Coleoptera, Carabidae) reflecting environmental conditions. Zookeys, 100, 287-317.

[17] Sukhodolskaya RA, Saveliev AA and Muhammetnabiev TR. (2016). Sexual Dimorphism of Insects and Conditions of Its Manifestation. Research Journal of Pharmaceutical, Biological and Chemical Sciences, 7(2), 1992 - 2001.

[18] Sukhodolskaya R, Saveliev A. (2016). Body size variation in Ground Beetles (Coleoptera: Carabidae). Periodicum Biologorum, 118(3), 273 - 278.

[19] Lovich JE and Gibbons JW. (1992). A review of techniques for quantifying sexual size dimorphism. Growth Development and Aging, 56, 269 - 281.

[20] Brigadirenko V and Korolev O. (2015) Morphological polymorphism in an urban population of Pterostichus melanarius (Illiger, 1798) (Coleoptera, Carabidae). Graellsia 71(1), 025.

[21] Stillwell RC and Fox CW. (2009). Geographic variation of body size, sexual size dimorphism and fitness components of a seed beetle: local adaptation versus phenotypic plasticity. Oikos, 118, 703 - 712.

[22] Romero ML, Rosetti N and Remis MI. (2014). Morphometric variation affecting sexual size dimorphism in Neopedies brunneri (Orthoptera: Acrididae). Annals of the Entomological Society of America, 107(1), 257-263

[23] Sukhodolskaya R. (2014). Variation in Body Size and Body Shape in Ground Beetle Pterostichus melanarius Ill. (Coleoptera, Carabidae). Journal of Agri-Food and Applied Sciences. 2(7), 196-205.

[24] Blanckenhorn WU, Stillwell RC, Young KA, Fox CW and Ashton KG.(2006) When Rensch meets Bergmann: does sexual size dimorphism change systematically with latitude? Evolution, 60, 2004-2011.

\section{How to cite this article}

Sukhodolskaya RA, Saveliev AA, Gordienko TA and Vavilov DN. (2018). Sexual size dimorphism in Ground Beetles and its modeling in latitude gradient. GSC Biological and Pharmaceutical Sciences, 3(1), 11-18. 